\title{
Presenting a Model of Organizational Insentience in the Red Crescent Society
}

\author{
Seyed Ali Salehi Koocheh Baghi ${ }^{1} \mathbb{D}$, Maryam Rahmaty $^{2} \mathbb{D}$, Davood Kia Kojouri ${ }^{3} \mathbb{D}$
}

\author{
Date of submission: 1June. $2021 \quad$ Date of acceptance: 9 Aug. 2021
}

\section{Original Article}

\section{Abstract}

INTRODUCTION: Organizational insentience has been one of the main challenges in recent years and refers to a situation in which employees of the organization have become indifferent to their organizational environment. This study aimed to design a model for dealing with organizational insentience in the Iranian Red Crescent Society.

METHODS: In this qualitative study, after investigating the phenomenon of organizational insentience and reviewing the theoretical foundations, in-depth interviews were conducted with experts, managers, and masters in the Red Crescent Society. Theoretical saturation was achieved after conducting 21 interviews. Subsequently, the data obtained from the interviews were analyzed through grounded theory and qualitative coding (open, axial, and selective coding).

FINDINGS: The findings showed that the main axial theme in this study was organizational insentience, and six themes of senselessness toward the concept of work, double standards, accountability, organizational discrimination, lack of strategic management procedures, and inability to implement policies were the requirements for dealing with organizational insentience, which were coded under the theme of causal conditions. In addition, such factors as decent governance, strengthening the psychological dimension, building trust, strengthening staff's skills, organizational independence, strengthening innovation and creativity, justice, supportive behavior, and supportive environment were selected as the main strategies to deal with organizational insentience.

CONCLUSION: It seems that the dominant organizational culture, along with management style and type of communication within the organization, has the main effect on the issue of organizational insentience.

Keywords: Organizational Insentience; Iranian Red Crescent Society; Grounded Theory.

How to cite this article: Salehi Koocheh Baghi SA, Rahmaty M, Kia Kojouri D. Presenting a Model of Organizational Insentience in the Red Crescent Society. Sci J Rescue Relief 2021; 13(3): 228-36.

\section{Introduction}

7 The The nature of an organization shows the key principles and practices of who we are and what we do and defines how individuals, as a member, reflect the nature and characteristics of their organizations (1). According to the high goals of the organization, one of the most important tasks of organizations is to motivate employees as the strategic assets of the organization. In the meantime, organizational negligence is a wrong behavior that if it penetrates the soul and body of the organization, the organization will suffer from chronic mental and motor retardation (2).
One of the consequences of neglecting human resources is the creation of a phenomenon called organizational insentience (3). Insentience in the organization is described as the behavior of an individual who mechanically and without using his genius and creativity makes organizational achievements without question. As a result, accepting the orders, which are far from any interest, although may seemingly maintain organizational order, does not motivate employees to strive, accept responsibilities, or show initiative (4). Sometimes people react to orders in the form of protests and strikes, which are the most obvious forms of dissatisfaction, and sometimes the high

1- PhD Student in Management, Chalous Branch, Islamic Azad University, Chalous, Iran

2- Assistant Professor, Department of Management, Chalous Branch, Islamic Azad University, Chalous, Iran

3- Associate Professor, Department of public administration, Chalous Branch, Islamic Azad University, Chalous, Iran

Corresponding author: Maryam Rahmaty, Email: rahmaty.maryam61@gmail.com 
absence of staff indicates this; however, what causes people to give up and become insentient is deep dissatisfaction for a long time (5).

Organizational insentience is caused by inattention to the organizational sensor and is a kind of failed sensing (6) and a process that is caused by expectations that are not met (7). Regarding the formation of the problem of organizational insentience, various components can be mentioned, including human resource management (8), meritocracy (9), organizational culture (10), manager-employee relationship (11), job alienation (12). These topics have been evaluated by researchers and their positive or negative role has been examined in the formation of organizational insentience. Considering the social aspects of organizational insentience, it can be concluded that one of the influential components on the formation of organizational insentience is the concept of social responsibility of organizations (13).

Indifferent employees not only do not create a competitive advantage for the organization but also increase organizational costs. In addition, the individual becomes unmotivated to achieve organizational goals (14). Therefore, organizational insentience occurs when the organization does not pay attention to sentient activities. Organizational insentience means indifference, hopelessness, numbness, and carelessness in the organization; nevertheless, sentient is the use of emotion alongside logic in the organization (15). Aguinis and Glavas (2017) suggested four factors that lead to individual sensemaking in the organization, namely work orientation, moral identity, environmental values, and communal values. Work orientation has been proposed as an important effective and significant factor in sensemaking in the organization (16).

Social identity, the structures associated with it, is as intermediaries that are often studied in the social responsibility literature of organizations (17-19). In addition, the self-concept of the individual (e.g., who am I?) forms what is meaningful (20). Although there is extensive literature on social identity, it takes more work and time to understand how people interpret it specifically in their field of work $(21,22)$. Values in this domain are important factors in sensemaking since they are the main source of meaning in the individual and the organization (20). Moreover, communal values refer to the ultimate desirable state of human well-being through the protection of basic human rights and the satisfaction of human needs (e.g., growth and dependence) (22).

Khamshaya et al. (2019) in a study entitled "A Metaphorical Interpretation of Organizational Insentience Phenomenon: Developing and Validation of a Conceptual Model" concluded that organizational insentience can be depicted in the form of a three-layer model. At the most fundamental layer of the conceptual model, the four factors of insentient roles, insentient events, general insentient development, and negative social sensory cognitions shape organizational insentience. At the outermost layer, organizational insentience manifests itself in the form of such behaviors as white fear and white identity, local organizational numbness, silent crisis, and organizational reluctance (23).

Organizational insentience affects most public institutions, such as the Red Crescent Society, and makes it difficult to pave the way for organizational goals. It is a situation that can be described as a destructive factor in the organization, in which the realization or nonrealization of the goals of the organization does not make difference for a member or a group of members and is considered a deviation from the balanced situation in the organization. In other words, the concept of organizational insentience is an event that is formed due to the neglect of some components or excess in the other ones in an organization and has negative effects on employees and the organization as a whole (24).

The Red Crescent Society of the Islamic Republic of Iran is a non-profit organization that acts as the custodian of the government in the field of the rescue operation and public education. This organization also provides assistance to people affected by natural and man-made disasters and is responsible to provide humanitarian assistance to vulnerable individuals in the community.

The prevention of the increase in organizational insentience among the employees of this organization is a highly important and effective issue for the management and officials of the Red Crescent Society. Therefore, considering the mentioned cases regarding the importance of organizational insentience and its considerable role in the dynamics of organizations, the present study aimed to provide a model for organizational insentience in the Red Crescent Society, and consequently, take an 
important step towards improving the effectiveness of this organization.

\section{Methods}

The qualitative present study was conducted based on grounded theory. The instrument employed to collect the required data was semistructured interviews. The statistical population consisted of all the academic experts (in the fields related to human resources and organizational behavior of managers) and Red Crescent Society maters (in relief organizations; Deputy of Health, Treatment and Rehabilitation; and rapid response teams) with at least a 4-year management experience and at least a master's degree. The samples were collected by theoretical sampling using non-probability targeted and snowball sampling techniques.

In the present study, data saturation was reached until the performance of 21 semistructured interviews. The interviewees consisted of individuals with a PhD degree $(n=9)$, Master's degree $(n=10)$, and bachelor's degree $(n=2)$ with $11-25,11-30$, and 18-22 years of work experience, respectively. Data analysis in the present study was based on the systematic approach proposed by Strauss and Corbin (1998), in which qualitative data analysis for theorizing requires the use of open coding, axial coding, and selective coding. In the present study, in addition to the organization of structured processes for recording, writing, and interpreting data, a steering committee evaluated and implemented the interview program.

\section{Findings}

Data analysis of this study was performed in the Red Crescent Society according to the instructions of Strauss and Corbin. This method includes three main stages of open coding, axial coding, and selective coding. In the selective coding stage, based on the components obtained at the axial coding stage, research propositions are presented. Therefore, in this study, based on the dimensions of the coding paradigm, the analysis of interview data was explained.

In the open coding stage, the data obtained from the interviews were carefully reviewed and the main themes and sub-themes related to them were identified. The main units of analysis for open coding were concepts. During this coding process, 341 open codes, 89 concepts, and 29 categories were extracted and their characteristics were identified in the Red Crescent Society. Axial coding is the process of linking categories to subcategories and relating categories at the level of features and dimensions. In this step, the grounded theorist selects a category from the open coding step, places it at the center of the process under consideration, and relates the other categories to it.

In this study, while open coding, the data were divided into separate sections and carefully studied to obtain similarities and differences, which resulted in numerous themes. During the iterative process of data analysis, the collection of these initial qualitative data was reduced to fewer themes, so that from within the raw data, introductory themes related to the phenomenon under study were extracted. Moreover, similarities and differences were derived by asking about data, comparing cases, events, and other states of each phenomenon. In the next step (i.e., axial coding), other themes were theoretically related to the main theme or axial phenomenon. Based on the analysis of qualitative data, the axial coding stage was completed, according to which, the line of communication between the research themes, including causal conditions, pivotal theme, contextual conditions, intervening conditions, strategies and consequences was identified.

\section{Causal conditions}

Causal factors include items that directly affect the phenomenon of organizational insentience or, in some way; these factors create and develop the phenomenon. Table 1 tabulates the themes and sample codes extracted from the interview in the causal conditions section of the present study.

\section{Contextual conditions}

Contextual conditions are factors without which the realization of organizational insentience is impossible. The prevailing context provides specific conditions in which strategies for managing, controlling, and responding to the phenomenon are provided. These conditions constitute a set of contextual concepts, themes, or variables. Table 2 presents the subthemes and sample codes in the context conditions section.

\section{Axial theme}

The axial theme in grounded theory is the phenomenon that is the main field of research and all other themes are related to it. Table 3 summarizes the categories and sample codes in the axial theme section. 
Table 1. Sample codes in the causal conditions section

\begin{tabular}{|c|c|c|}
\hline Concepts & Sub-themes & Main theme \\
\hline Feeling useless & \multirow{6}{*}{$\begin{array}{l}\text { Feeling meaningless } \\
\text { Towards the concept of } \\
\text { work }\end{array}$} & \multirow{20}{*}{$\begin{array}{l}\text { Causal } \\
\text { conditions }\end{array}$} \\
\hline Consequential thinking & & \\
\hline Mutual justification and understanding between managers and employees & & \\
\hline Seriousness & & \\
\hline Culture of ridicule & & \\
\hline Materialism & & \\
\hline Procedural injustice & \multirow{2}{*}{ Double standard } & \\
\hline Inequality in the organization & & \\
\hline Lack of accountability culture & Accountability & \\
\hline Gender discrimination & \multirow{2}{*}{$\begin{array}{l}\text { Organizational } \\
\text { discrimination }\end{array}$} & \\
\hline Ethnic discrimination & & \\
\hline Inefficient performance measurement & \multirow{3}{*}{$\begin{array}{l}\text { Lack of } \\
\text { strategic management } \\
\text { procedures }\end{array}$} & \\
\hline Lack of scenario writing & & \\
\hline Lack of perspective & & \\
\hline \multirow{2}{*}{\multicolumn{2}{|c|}{$\begin{array}{c}\text { Ambition and irrationality of plans } \\
\text { Unplanned organization }\end{array}$}} & \\
\hline & & \\
\hline Disproportion between possessions and desires & \multirow{4}{*}{$\begin{array}{l}\text { Inability to perform } \\
\text { policies }\end{array}$} & \\
\hline Lack of human resources & & \\
\hline Lack of physical resources & & \\
\hline Individual disabilities & & \\
\hline
\end{tabular}

Table 2. Sample codes in the contextual conditions section Sub-themes Concepts

Concepts
Non-participatory procedures
Top-down management
Unfair treatment toward employees
Ignorance of work values
Lack of staff support
Fear of unintended consequences
Culture of continuity

Concern about the negative consequences of participation Immediate decision-making Intra-organizational communication Lack of common destiny Service unanswered Organizational politicization Mismatch between reward and punishment Insufficiency of performance evaluation indicators Corrupt system of recruitment

\section{Structural dimensions}

Cognitive dimensions

Emotional dimensions

White fear

Intuitive management style Insignificant organizational social capital

Lack of meritocracy
Contextual conditions

\section{Intervening conditions}

The intervening condition deal with the modification of causal conditions and influences strategies and interactions. Table 4 shows the themes and sample codes in the intervening conditions section.

\section{Strategies}

Strategies represent the interactions and actions that actors take in response to those situations. The axial phenomenon can be realized through using tactics and strategies. (Table 5)

\section{Consequences}

The purpose of this section is to identify the concepts and themes related to the consequences of applying organizational insentience strategies. Strategies are adopted against or to manage and control a phenomenon and have consequences. Table 6 presents the themes and sample codes in the consequences section.

Based on the components of the axial coding stage, the following propositions were obtained: 
Proposition 1. Feeling meaninglessness toward the concept of work, double standards, accountability, organizational discrimination, lack of strategic management procedures, and inability to implement policies impacted organizational insentience as causal conditions.

Table 3. Sample codes in the axial theme

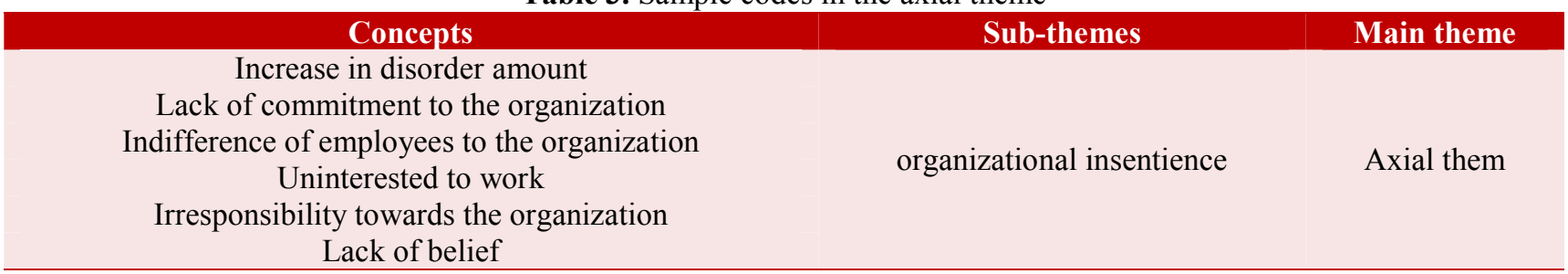

Table 4. Sample codes in the intervening conditions section

Concepts

Sustainable policies

Individualism instead of teamwork

Flattery culture

Coordination

Seeking excuses

Laziness culture

Materialism

Responsibility avoidance

Lack of self-confidence

Low skills of staff

Self-determination and despotism Low self-esteem

\section{Sub-themes}

Organizational Culture

General culture of the community

Intervening conditions

Individual disqualifications

Individual characteristics

Table 5. Sample codes in the strategies section Concepts Sub-themes

Expanding transparency in inter-organizational procedures

Strengthening accountability

Participatory decision-making

Strengthening self-esteem among employees

Creating job security

Providing livelihood services

Encouraging empathy among employees

Encouraging altruism among employees

Holding in-service classes

Using young and educated forces alongside old forces for succession planning

Applying empowerment policies

Consigning some authorities

Avoiding politics

Encouraging innovation and creativity

Paying attention to individual abilities in employment Justice in procedure

Justice in performance assessment Observing rules

Strengthening the spirit of empathy Emotional support

Decent governance

Strengthening the psychological dimension

Creating an atmosphere of trust

Strengthening staff's skills

Organizational independence

Strategies

Strengthen innovation and creativity

Justice

Supportive behavior

Preventing the occurrence of job burnout

Strengthening organizational commitment Spreading altruism

Strengthening self-sacrifice

Supportive environment

Strengthening the sense of belonging among employees 
Table 6. Sample codes in the consequences section

Main theme Sub-themes

Individual consequences

Consequences
Concepts

Job satisfaction

Improving individual performance

Expanding intra-organizational cooperation

Strengthening innovation and creativity

Feeling valued

Organizational agility

Promoting organizational brand

Increasing organizational belonging

Decreasing desire to quit

Increasing the spirit of participation and innovation

Customer satisfaction

Formation of organizational citizenship behavior

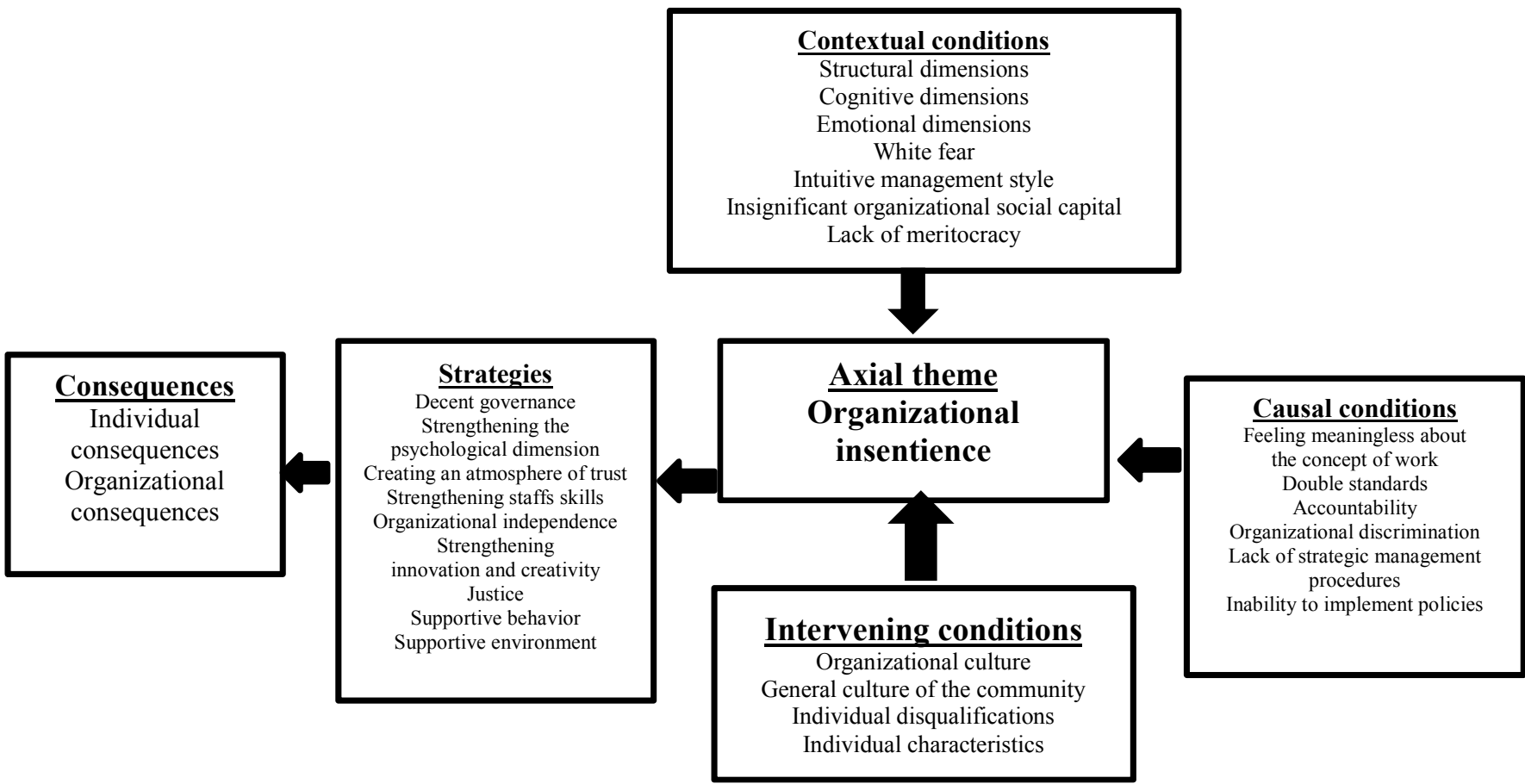

Figure 1. Final model of organizational insentience in the Red Crescent Society of the Islamic Republic of Iran

Proposition 2. Structural dimensions, cognitive dimensions, emotional dimensions, white fear, intuitive management style, and insignificant organizational social capital, affected organizational insentience as the contextual conditions.

Proposition 3. Decent governance, strengthening the psychological dimension, creating a trustworthy atmosphere, strengthening employees' skills, strengthening innovation and creativity, central justice, supportive behavior, and organizational independence were the main strategies for organizational insentience.
Proposition 4. Organizational culture, society's general culture, individual inadequacies, and individual characteristics affected organizational insentience as intervening conditions.

Proposition 5. Causal conditions, contextual conditions, intervening conditions, and strategies, would lead to agenda consequences and organizational insentience consequences (e.g., individual consequences and organizational consequences). 


\section{Discussion and Conclusion}

This study aimed to explain the conceptual model of organizational insentience with open, axial, and selective coding procedures and was conducted in the Red Crescent Society based on the grounded theory. Interview data were coded by Strauss and Corbin method. The findings of this study include the fact that a set of individual and organizational causes are involved in the formation of organizational insentience in the Red Crescent Society and it is necessary to adopt a strategy at different levels to prevent its occurrence.

The results of studies have shown that the main reasons for the formation of organizational insentience in the Red Crescent Society should be sought in the management of human resources governing the organization. In this regard, organizational insentience is less likely to occur when this structure is closer to meritocracy practices. It should also be noted here that the consequences of organizational insentience generally affect the organization, although the individual himself is influenced by it and accepts its negative effects. In the meantime, to prevent the occurrence of organizational insentience, organizations should adopt policies that allow them to give individuals the opportunity to advance by creating a competitive and healthy environment and placing them in their specialty positions. The main strategy to get out of the current situation is to restore the spirit of usefulness and actuality to employees.

One of the main reasons for the formation of insentience in the Red Crescent Society is the concept of the job. If the concept of the job is shaped in a way that a person cannot communicate with it, he will feel highly alienated from the job and will eventually lose his roots and connections. Underlying the problem of foresight lies the fact that the formation of organizational insentience is an event that occurs in the middle of the path for numerous organizations, and it is not the case that an organization is involved in this phenomenon from the beginning.

In organizations that are moving on track, if there is no replacement for managers and no action is taken to maintain the desired situation, it is highly probable that the employees will be dismissed and the long-term and strategic goals of the organization will be forgotten, leading to the formation of insentience. However, the method adopted to human resource management is the most important and frequent category among the causes of insentience formation. Regarding this, insentience is a product that arises from the individual's knowledge of his/her situation and that of the organization in relation to other employees and managers.

Organizations that do not employ meritocracy models in attracting human resources and do not regulate the system of rewards, promotions, and punishments according to the performance of employees are always at risk of insentience in parts of the organization. When innovation and knowledge employees feel on par with individuals who do not deserve to be in the organization, it causes them to lose their sense of organizational activity. The main contextual conditions in the present study included lack of decent governance, political interference, organizational culture, and organizational alienation. Lack of decent governance, accountability, and transparency cause competent employees to be discouraged in carrying out their activities and unable to perform their duties.

Another aspect of this problem is that in the absence of accountability, inefficient and corrupt managers of organizations find the opportunity to turn the organization into an arena for their personal purposes and exploit it in any possible way. Political interventions lead to the formation of a situation in which the organization seeks to achieve the goals of other political bodies rather than pursuing its own goals. Political interventions make the organization's strategies ineffective in preventing the organizational insentience and unbales the organization to respond to strategies to get out of its situation.

Organizational culture is another component of the contextual conditions that causes organizational insentience. Organizations that are agile and open to criticism and plan for their strategic goals have the flexibility to change their situation and modify themselves. In such a situation, what is necessary is to reform the organizational culture since the continuation of the wrong organizational culture leads to the formation of organizational alienation, which is one of the roots of organizational insentience. Furthermore, what was most emphasized in the expert interview was that white fear and injustice needed to be considered the main intervening component in this field.

White fear refers to the fears that an employee 
expects about his/her actions in the organization. In fact, due to the uncertain situation of the organization, the employees are afraid that their participation or convergence in the organization will cause negative consequences for them. White fear is the fear of being in unforeseen situations that leads to unpredictable consequences for employees' future careers. Employees who do not receive good feedback on exposing corruption or volatility in the organization become discouraged over time and prefer to neglect current events in the organization, and as a result, become less sensitive. Naturally, a set of strategies is needed to be adopted to correct such a procedure.

Strategies are specific actions or interactions that result from the axial phenomenon and the main strategies to prevent organizational insentience are strategic management, justice, and communication system strengthening. In other words, one of the causes of the formation of insentience is that employees in an organization move to the unknown instead of having a specific goal. As a result, the application of strategic principles plays an important role in preventing organizational insentience.

Justice is another strategy to cure insentience since insentience is the product of a sense of injustice in the organization. It is less likely for organizational insentience to occur when employees recognize the organization's situation highly in accordance with justice. In this condition, the expansion of communication and strengthening of internal communication between employees and managers lead to the creation of a more positive feeling between individuals. This issue will result in the generation of trust and cooperation between employees and the reduction of organizational insentience. Outcomes are the output that is obtained with the implementation of strategies.

Organizational insentience has two spectrums of individual and organizational consequences.

Regarding this, demotivation, organizational isolation, stopped growth and learning, and the desire to leave the job should be considered the main consequences that will arise if the above strategies are not applied to employees and overshadow the employee's individual and organizational performance. Moreover, organizational consequences, such as financial loss, customer loss, customer dissatisfaction, internal failures, and inconsistencies between organizational departments can overshadow the organization.

\section{Acknowledgments}

The authors would like to express their gratitude to all those who contributed to the conduction of this research project.

\section{Conflict of Interests}

The authors declare that there were no conflicts of interest in this study.

\section{References}

1. Gephart Jr RP. The textual approach: Risk and blame in disaster sensemaking. Acad Manage J 1993; 36(6):1465-514.

2. Hill RC, Levenhagen M. Metaphors and mental models: Sensemaking and sensegiving in innovative and entrepreneurial activities. Journal of Management 1995; 21(6):1057-74.

3. Sonenshein $\mathrm{S}$. The role of construction, intuition, and justification in responding to ethical issues at work: The sensemaking-intuition model. Acad Manage Rev 2007; 32(4):1022-40.

4. Westbrook L. Qualitative research methods: A review of major stages, data analysis techniques, and quality controls. Libr Inf Sci Res 1994; 16(3):24154.

5. Dutton JE, Roberts LM, Bednar J. Pathways for positive identity construction at work: Four types of positive identity and the building of social resources. Acad Manage Rev 2010; 35(2):265-93.

6. Johnson RB, Christensen L. Educational research: Quantitative, qualitative, and mixed approaches. 7th ed. SAGE Publications, Inc; 2019; p 704

7. Boroumand NR, Reihani Yasavoli A, Ahmadzadeh A. The Effect of Organizational Indifference on the Efficiency of Nurses in Public Hospitals of Mashhad. Iranian Journal of Nursing Research 2018; 10; 12(6):19-23. (In Persian)

8. Ahmadi SA, Rafiee A. A study on emotional intelligence strategies to reduce organizational indifference. International Journal of Management Research and Business Strategy 2015; 4(3):168-78. (In Persian)

9. Jones DA. Does serving the community also serve the company? Using organizational identification and social exchange theories to understand employee responses to a volunteerism programme. J Occup Organ Psychol 2010; 83(4):857-78.

10. Moradi M, Hamidi HR, Eskandari A. Investigating the Relationship between Organizational Indifference, Organizational Justice, and Organizational Belonging among Librarians and Employees at the Astan-e Quds Razavi's Organization for Libraries, Museums, and Document 
Centers. Library and Information Sciences 2019; 23(1): 5-27. (In Persian)

11. Rostami S, Mirzaei Sharifi H, Hasan Porgavkosh Y, Hemmati P. Investigating the Relationship between Leadership Style and Organizational Silence and Organizational Indifference in Primary School Principals and Deputies of Delfan County, 8th National Conference on Sustainable Development in Educational Sciences and Psychology, Social and Cultural Studies, Tehran. Iran. 2020. (In Persian)

12. Pratt, Michael, et al. "Doing Well, Doing Good, and Doing with: Organizational Practices for Effectively Cultivating Meaningful Work." Purpose and Meaning in the Workplace, In: Bryan J Dik et al. editors. American Psychological Association 2013; 173-96.

13. Catino M, Patriotta G. Learning from errors: Cognition, emotions and safety culture in the Italian air force. Organization studies 2013; 34(4):437-67.

14. Drazin R, Glynn MA, Kazanjian RK. Multilevel theorizing about creativity in organizations: A sensemaking perspective. Acad Manage Rev 1999; 24(2):286-307.

15. Glaser B, Strauss AL. The constant comparative method. The discovery of grounded theory: strategies for qualitative research. New York: Aldine De Bruyter. 1967:101-5.

16. Gioia DA, Thomas JB. Identity, image, and issue interpretation: Sensemaking during strategic change in academia. Adm Sci Q 1996; 41(3):370-403.

17. Danaeifard H, Hasanzadeh A, Salarieh N. Organizational Indifference Measurement Design: Combined Research, Strategic Management
Thought (Management Thought). Journal of "Strategic Management Thought (Scientific Thought) 2000; 4(3): 79-99(In Persian)

18. Glavas A, Kelley K. The effects of perceived corporate social responsibility on employee attitudes. Business Ethics Quarterly 2014; 24(2):165-202.

19. Marcus J, MacDonald HA, Sulsky LM. Do personal values influence the propensity for sustainability actions? A policy-capturing study. J Bus Ethics 2015; 127(2):459-78.

20. Rudolph JW, Morrison JB, Carroll JS. The dynamics of action-oriented problem solving: Linking interpretation and choice. Acad Manage Rev 2009; 34(4):733-56.

21. Farooq O, Payaud M, Merunka D, Valette-Florence $\mathrm{P}$. The impact of corporate social responsibility on organizational commitment: Exploring multiple mediation mechanisms. Journal of Business Ethics 2014; 125(4):563-80.

22. Aguinis H, Glavas A. On corporate social responsibility, sensemaking, and the search for meaningfulness through work. Journal of management 2019; 45(3):1057-86.

23. Khamshaya A, Shiri A, Yasini A. A metaphorical interpretation of the phenomenon of organizational insentience in governmental organizations: analysis of strategies and consequences. Public Administration Perspective 2019; 10(2):187-215. (In Persian)

24. Sonenshein S. We're changing-or are we? Untangling the role of progressive, regressive, and stability narratives during strategic change implementation. Academy of Management Journal. 2010; 53(3):477-512. 